\title{
Tell Me What You Want: Disentangling the Impact of Service Specification Option Repertoires on Service Performance in Gig Economy
}

\author{
Shaoxiong Fu \\ Wuhan University \\ fu_shaoxiong@163.com
}

Fei Liu

Copenhagen Business School

afl.digi@.cbs.dk

\author{
Yuting Jiang \\ Wuhan University \\ jhai_jiang@whu.edu.cn
}

Eric T. K. Lim

University of New South Wales

e.t.lim@unsw.edu.au

\author{
Zhao Cai \\ University of Nottingham Ningbo China \\ Zhao.Cai@nottingham.edu.cn
}

\author{
Chee-Wee Tan \\ Copenhagen Business School \\ ct.digi@cbs.dk
}

\begin{abstract}
Confronted with an increasingly competitive landscape for credence services in the gig economy, workers on gig economy platforms are compelled to compete by configuring the service specification options on such platforms to enhance the visibility of their gig offerings. Motivated by a dearth of research on the effects of discrete configurations of service specification options on service quality and sales, this study builds on competitive repertoire theory to advance a research model that seeks to unveil how the volume, complexity, and heterogeneity of service specification option repertoires affect service quality and sales. We empirically validate our hypotheses with a dataset comprising 3,307 lifestyle-themed credence services from Fiverr, one of the largest e-marketplaces for gig economy in the world. We discover that repertoire volume is positively associated with both service quality and sales whereas repertoire complexity is only positively associated with service quality. Repertoire heterogeneity, on the other hand, is neither associated with service quality nor with sales.
\end{abstract}

\section{Introduction}

Unlike the traditional job market which guarantees permanent employment, gig economy is a dynamic labor market system in which employers (or consumers) engage independent workers on short-term contracts [1, 2]. With the aid of digital platforms, gig economy is becoming an emerging alternative labor market with spending estimated at USD \$3.7 trillion globally [3]. According to recent statistics, USD $\$ 864$ million of revenue was generated by 48 million gig workers in 2017, accounting for approximately $31 \%$ of the total workforce in America [3]. Gig economy platforms in the likes of Amazon Flex, Fiverr, and Wonolo, can be conceived as digital on-demand platforms that offer flexible and temporary job arrangements whereby workers deliver services to satisfy the needs of their employers [1]. Taking Fiver as an illustration, it has emerged as one of the largest gig economy platforms worldwide, boasting of 125 distinct types of services that are in demand by more than 11 million businesses [4]. Because there is a diversity of workers to choose from for each type of service (e.g., graphics and design) offered on gig economy platforms due to low entry barriers, such platforms breed intense competition among workers. Consequently, a common dilemma confronting workers on gig economy platforms is how to differentiate their gig offerings from those of their immediate rivals.

Most gig offerings are credence services that comprise attributes for which consumers cannot verify even after consumption $[5,6]$. This in turn translate into challenges for employers when engaging workers on gig economy platforms. Not only is it difficult for employers to formulate expectations for gig offerings due to a lack of awareness over how these offerings can fulfill their needs [8], it is equally hard for employees to assess the eventual utility of gig offerings due to an obscure servicing process [7]. Consequently, prior research has advocated the provision of comparative information as a means of enhancing the verifiability of credence services [9]. Through comparing credence services, consumers can build up their expertise in evaluating such services and reduce the risk associated with their consumption $[5,10]$. Furthermore, consumers can gain confidence in making purchase decisions if they are able to appreciate how deliverables of credence services can fulfill their needs $[7,11]$. But at the same time, it should be noted comparative information on credence services remains fragmented due to their indeterminate nature $[9,10]$. In this sense, it is imperative for gig economy platforms to offer functions that standardize the specification of credence services to 
assist employers in comparing and contrasting gig offerings.

'Compare Packages' (See Figure 2) is a service specification function that standardizes information to guide consumers in their decision-making. Noticeably, a myriad of specification options in the likes of package, delivery time, and revisions, are available to sellers to allow them to supply standardized information to eliminate consumers' uncertainty over credence services. Although past studies have explored the performance impact of service specification as a holistic function $[12,13]$, little attention has been paid to the breakdown of this function by investigating the configuration of service specification options. For this reason, there is a necessity for workers (or sellers) to comprehend how repertoires of service specification options can be harnessed to bolster their service performance in highly competitive and nascent emarketplaces such as the gig economy, which in turn acts as the main impetus for our study.

To this end, we build on Competitive Repertoire Theory (CRT) to advance a research model that elucidates how service specification option repertoires affect service performance in the context of gig economy. CRT originates from the field of strategy and has been applied to e-marketplaces in past studies [14]. CRT holds that one's performance in competitive markets is determined by the configuration of competitive action repertoires [14]. Grounded in CRT, we espouse three structural characteristics, namely volume, complexity, and heterogeneity, to capture the configuration of service specification option repertoires in its multifaceted form [14]. By extracting and analyzing data from a predominant gig economy platform - Fiverr, this study strives to answer the following research question: How do the volume, complexity, and heterogeneity of service specification option repertoires relate to the quality and sales of service offerings on gig economy?

In the next section, we present an overview of extant literature on the performance impact of platform-based functions in e-marketplaces and introduce CRT as an appropriate theoretical lens for constructing our research model. After formulating the hypotheses for our research model and describing the methodological procedures we employed for validating the model, we discuss our empirical findings as well as their implications for theory and practice. We conclude by highlighting the limitations of this study and outlining avenues for future work.

\section{Theoretical Foundation}

\subsection{Performance of service specification option repertoire in e-marketplaces}

Because e-marketplace constitutes a platformized market to facilitate transactional exchanges between consumers and sellers, service specification functions are often provided as a means for sellers to display their goods to consumers $[15,16]$. Likewise, on gig economy platforms, sellers offer services known as 'gigs'. Gig economy platforms provide service specification functions that can be configured by sellers to provide information to consumers, such as gig packages, image and video display as well as frequently asked questions. In our study, service specification functions are ITenabled configurable functions that are (1) supported by the platform, (2) activated at the seller's discretion, as well as; (3) externally observable so as to attract and retain consumers [17]. Sellers design service specification by employing options embedded in the platform. The variance in selecting and designing options determines their different service performance influences. Taking Figure 2 as an example which is the function of "compare package" - a service specification function in Fiverr, this case includes 9 service specification options in 3 categories which are package, revisions, and delivery time.

Existing research has examined the impact of service specification functions on the service performance but revealed inconsistent conclusions. For example, the specification of money-back guarantee in emarketplaces can act as an effective quality or credibility indicator, which shows positive relationship with service performance [18, 19]. Likewise, specification on customer protection scheme was found to positively associate with service performance [18]. However, insignificant relationship between this specification and service performance was reported by Bockstedt and Goh [20]. The underlying reason of these contradictory findings can be attributed to the lack of discussion on the options within each service specification function. By scrutinizing different roles of options, in-depth insights can be generated on how to utilize the portfolio of options in a service specification function to promote service performance [14]. Since most sellers adopt a combination of service specification options to provide information which cannot be easily imitated by competitors $[21,22]$, a portfolio method would be much suitable for the gig economy context [20]. In this vein, service specification option repertoire is employed by this study to refer to the set of service specification options designed by a seller. This study investigates the relationship between service specification option repertoires and service performance in order to provide insights on how to utilize option 
repertoires to achieve a better performance in gig economy.

\subsection{Competitive repertoire theory}

CRT is a theoretical framework to comprehend temporary competitive advantages from the perspective of structural options of sellers' competitive repertoires [14]. Repertoire refers to a series of actions carried out by a seller to attract, support, and maintain consumers, which is a creative method to assess the strategy of sellers [23]. CRT suggests that a seller's performance outcomes can be determined by its competitive actions $[24,25]$. Competitive action refers to any marketoriented, specific, observable, external-oriented competitive options that a seller adopts to improve its market position [25]. This theory therefore conceptualizes the service specification options as a repertoire of competitive actions in gig economy to promote service performance. CRT focuses on three structural features of competitive action repertoires, namely, repertoire volume, repertoire complexity, and repertoire heterogeneity [26].

IS scholars have adopted CRT to interpret the utilization of competitive action repertoires in attaining satisfactory performance [27, 28]. As illustrated in Table 1, CRT is an appropriate theoretical lens interpreting the impact of competitive actions on service performance in e-marketplaces. Specifically, for credence services in gig economy, sellers need to display the information through a repertoire of competitive action to reduce concerns from consumers. It is acknowledged that such competitive actions are represented by service specification options which help consumers attain more information on credence services and how these services fulfill their needs [14]. However, it remains unclear that how to utilize service specification option repertoires in terms of its volume, complexity, and heterogeneity to promote seller's service performance. The current study is an attempt to address this gap by utilizing CRT in gig economy platforms.

\begin{tabular}{|c|c|c|c|}
\hline Author & Context & Elements & Finding \\
\hline $\begin{array}{l}\text { Ferrier \& Lyon } \\
(2004) \text { [27] }\end{array}$ & $\begin{array}{l}\text { Firms in Airline } \\
\text { Industry }\end{array}$ & $\begin{array}{l}\text { Competitive } \\
\text { repertoire } \\
\text { simplicity; } \\
\text { Strategic repertoire } \\
\text { simplicity }\end{array}$ & $\begin{array}{l}\text { Competitive repertoire simplicity shows negative } \\
\text { relationship with firm performance. Strategic repertoire } \\
\text { simplicity is positively related to firm performance induced } \\
\text { by heterogeneous TMTs, and negatively related to less } \\
\text { heterogeneous TMTs. }\end{array}$ \\
\hline $\begin{array}{l}\text { Gnyawali, Fan, } \\
\text { \& Penner } \\
(2010)[28]\end{array}$ & $\begin{array}{l}\text { Social } \\
\text { Networking } \\
\text { Firms }\end{array}$ & $\begin{array}{l}\text { Complexity of } \\
\text { action repertoire; } \\
\text { Volume of actions }\end{array}$ & $\begin{array}{l}\text { Complexity of action repertoires exerts positive } \\
\text { relationship with firm performance, while the volume of } \\
\text { action repertoires shows insignificant relationship with } \\
\text { firm performance. }\end{array}$ \\
\hline $\begin{array}{l}\text { Chi, } \\
\text { Ravichandran, } \\
\text { \& Andrevski } \\
(2010)[26]\end{array}$ & Automaker & $\begin{array}{l}\text { Action volume; } \\
\text { Action complexity; } \\
\text { Action } \\
\text { heterogeneity }\end{array}$ & $\begin{array}{l}\text { Access to structural holes in firms' network is positively } \\
\text { related to action volume, action complexity, and action } \\
\text { heterogeneity, while network density is negatively related } \\
\text { to action volume, action complexity, and action } \\
\text { heterogeneity. }\end{array}$ \\
\hline $\begin{array}{l}\text { Zhang, Song, \& } \\
\text { Qu (2011) [29] }\end{array}$ & $\begin{array}{l}\text { Emerging } \\
\text { Markets }\end{array}$ & $\begin{array}{l}\text { Action repertoire } \\
\text { simplicity }\end{array}$ & $\begin{array}{l}\text { Action repertoire simplicity led by local vendors shows } \\
\text { positive relationship with the diffusion rate gap between } \\
\text { multinational firms' and local vendors' technology goods, } \\
\text { while action repertoire simplicity led by multinational } \\
\text { firms shows negative relationship with the diffusion rate } \\
\text { gap between multinational firms' and local vendors' } \\
\text { technology goods. }\end{array}$ \\
\hline $\begin{array}{l}\text { Connelly, } \\
\text { Tihanyi, } \\
\text { Ketchen Jr, } \\
\text { Carnes, and } \\
\text { Ferrier (2017) } \\
{[30]}\end{array}$ & $\begin{array}{l}\text { Publicly Traded } \\
\text { Firms }\end{array}$ & $\begin{array}{l}\text { Competitive } \\
\text { repertoire } \\
\text { complexity }\end{array}$ & $\begin{array}{l}\text { Competitive repertoire complexity negatively associates } \\
\text { with its short - term performance. Meanwhile, the } \\
\text { competitive repertoire complexity positively associates } \\
\text { with its performance trend, while the squared term of } \\
\text { competitive repertoire complexity negatively associates } \\
\text { with its performance trend. }\end{array}$ \\
\hline
\end{tabular}




\begin{tabular}{|l|l|l|l|}
\hline $\begin{array}{l}\text { Hughes- } \\
\text { Morgan, \& } \\
\text { Ferrier (2017) } \\
\text { [31] }\end{array}$ & $\begin{array}{l}\text { Pharmaceutical } \\
\text { Industry }\end{array}$ & $\begin{array}{l}\text { Action repertoire } \\
\text { intensity; } \\
\text { Action repertoire } \\
\text { complexity; } \\
\text { Action repertoire } \\
\text { non-conformity }\end{array}$ & $\begin{array}{l}\text { Short interest pressure positively associates with action } \\
\text { repertoire intensity and action repertoire non-conformity } \\
\text { and insignificantly associates with action repertoire } \\
\text { complexity. }\end{array}$ \\
\hline $\begin{array}{l}\text { Connelly, Lee, } \\
\text { Tihanyi, Certo, } \\
\text { and Johnson } \\
\text { (2019) [32] }\end{array}$ & Fublicly Traded & $\begin{array}{l}\text { Competitive } \\
\text { dissimilarity }\end{array}$ & $\begin{array}{l}\text { Rival firms with common ownership patterns will involve } \\
\text { in dissimilar competitive action repertoires to prevent } \\
\text { direct competition with each other. Competing } \\
\text { aggressively with dissimilar action repertoires makes } \\
\text { competitors keep high performance. }\end{array}$ \\
\hline $\begin{array}{l}\text { Li, Fang, Lim, } \\
\text { and Wang } \\
\text { (2019) [14] }\end{array}$ & E-marketplace & $\begin{array}{l}\text { Repertoire volume; } \\
\text { Repertoire } \\
\text { complexity; } \\
\text { Repertoire } \\
\text { heterogeneity }\end{array}$ & $\begin{array}{l}\text { Sales performance shows positive relationship with } \\
\text { platform-based structural features heterogeneity, high } \\
\text { complexity, and large volume. }\end{array}$ \\
\hline
\end{tabular}

\section{Research Model and Hypotheses Formulation}

Based on CRT, a research model is developed to examine the relationship between service specification option repertoires and service performance (See Figure 1). Specifically, repertoire volume, complexity, and heterogeneity constitute structural features of service specification option repertoires, which are proposed to be positively related to service performance represented by quality and sales. Prior research indicated that seller level and service type may associate with service performance $[14,33]$. We thus incorporate seller level and service type as control variables into our research model.

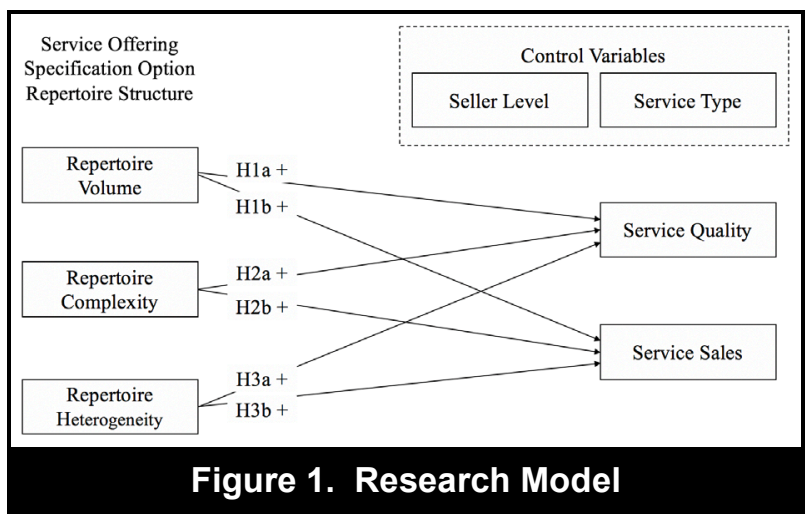

\subsection{Repertoire volume}

Repertoire volume refers to the number of service specification options employed by sellers to facilitate competitive actions $[14,27]$. As the volume of options configured by a seller increases, requirements from consumers can be externalized with a standardized format and precise information. The seller can provide service with a clear target to fulfill consumers' needs which are expressed accurately. A high level of service quality is more likely to achieve. Existing literature are also replete with evidence of the positive relationship between the number of service specification options and service quality. For example, it is reported that the number of emotion-related options on the platform, such as music, colors, and pictures, positively associates with customers' preference for services [34, 35]. Likewise, the number of options combining with design elements (e.g., personalized greetings, videos, pictures) are validated to positively associate with the perceived enjoyment through conveying a feeling of sociability and pleasure $[36,37,38]$. It is also verified that the diversity of service specification options positively connects with the perceived usefulness and perceived enjoyment of service [34]. Owing to the role of repertoire volume in externalizing consumer requirements and inducing positive emotion and cognition related to services, we therefore hypothesize that:

Hypothesis 1a. Service specification option repertoire volume of a gig is positively related to its service quality.

Repertoire volume in service specification represents the richness of information provided to the consumers to help them understand details of services. In gig economy platforms, the credence nature of service offerings impedes employers from purchasing because of the difficulty to verify its utility [5]. When sellers use a large volume of options, the service offering can be described with standardized and accurate information. Consumers can learn from this information and become confident in verifying credence services [14]. Consumers are more willing to make 
purchase when perceived uncertainty is decreased with a large number of options provided to them. Therefore, the more service specification options the seller sets, the greater the probability that the consumer will purchase the services. We hypothesize that:

Hypothesis $1 \boldsymbol{b}$. Service specification option repertoire volume of a gig is positively related to its service sales.

\subsection{Repertoire complexity}

Repertoire complexity is defined as the scope of different categories of service specification options employed by sellers [14]. Service specification options can be divided into different categories according to services provided in compare packages function. The repertoire complexity closely parallels the perceived ease-of-use which is the extent to which a consumer believes that using a particular service would be free of efforts [39, 40]. Complex option settings reduce perceived ease-of-use of services [41, 42]. After investing a high level of cognitive effort to use complex services, consumers' satisfaction will be undermined as a consequence [43]. The importance of ease-of-use becomes more salient in credence services because consumers lack expertise to evaluate quality of services. They are inclined to use simple portfolio of information to understand and verify credence services. Complex option repertoires cause confusion to consumers, which in turn leads to the low evaluation of service quality. We therefore hypothesize that:

Hypothesis 2a. Service specification option repertoire complexity of a gig is negatively related to its service quality.

Similarly, the complexity of service specification option that sellers configure could have a profound relationship with service sales [44]. As credence services are complicated and vague, a complex option repertoire makes purchase decisions more difficult, which in turn alienates consumers [30]. Moreover, complex competitive options are negatively related to the perceived ease-of-use of services, which in turn negatively associates with the intention of consumers to purchase $[45,46]$. In contrast, a simplified repertoire allows for an efficient option configuration that can help sellers to describe their services in an understandable and clear way [47]. It can highlight the most advantageous features of the service, avoid disrupting consumers' purchasing decisions by providing excessive information [48]. We therefore hypothesize that:

Hypothesis 2b. Service specification option repertoire complexity of a gig is negatively related to its service sales.

\subsection{Repertoire heterogeneity}

Repertoire heterogeneity refers to the option differences between compare packages, which is reflected by the differences between the number of service specification options in the basic, standard, and premium packages of a gig and the corresponding average number of all gigs in the platform (See Figure 2 ). Service with a high repertoire heterogeneity provides more options comparing to other services in the platform. Consumers perceive a high level of autonomy of customizing service when making comparison with other services, which makes the service with heterogeneous option repertoires more popular amongst its competitors [49]. Due to the feasibility of high-level customization, consumers can easily find the service offering which cater to their preferences, thereby providing higher evaluation to service quality [24]. Accordingly, the heterogeneous option repertoires enable service fulfilling consumers' various demands, which positively associate with the service quality [50]. We therefore hypothesize that:

Hypothesis 3a. Service specification option repertoire heterogeneity of a gig is positively related to its service quality.

The heterogeneity of option repertoires also promotes sales performance when competing with other sellers in the platform. A high level of heterogeneity indicates a strong capability of the seller to deliver highquality service to consumers because it can address all the customized requirements raised by options [51]. With this belief, consumers are willing to make purchase based on their trust in competence. Besides, heterogeneous option repertoires are positively related to the barrier of imitation from competitors. Other sellers in the platform can hardly replicate the business model of the ones with heterogeneous option repertoires [52]. As a consequence, service with a high level of heterogeneity in specification options positively associates with consumer's purchase intention and maintain this competitive advantage for a long period of time [53]. We therefore hypothesize that:

Hypothesis $3 \boldsymbol{b}$. Service specification option repertoire heterogeneity of a gig is positively related to its service sales.

\section{Methodology}

\subsection{Data collection}

Data were collected from Fiverr which is one of the largest gig economy platforms. Specifically, we chose gigs in the section of lifestyle of Fiverr where all gigs are credence services. In all, detailed information of 
3,307 gigs was collected by March 18, 2019. Figure 2 displays an example of the service specification in the function of compare packages of a gig in Fiverr.

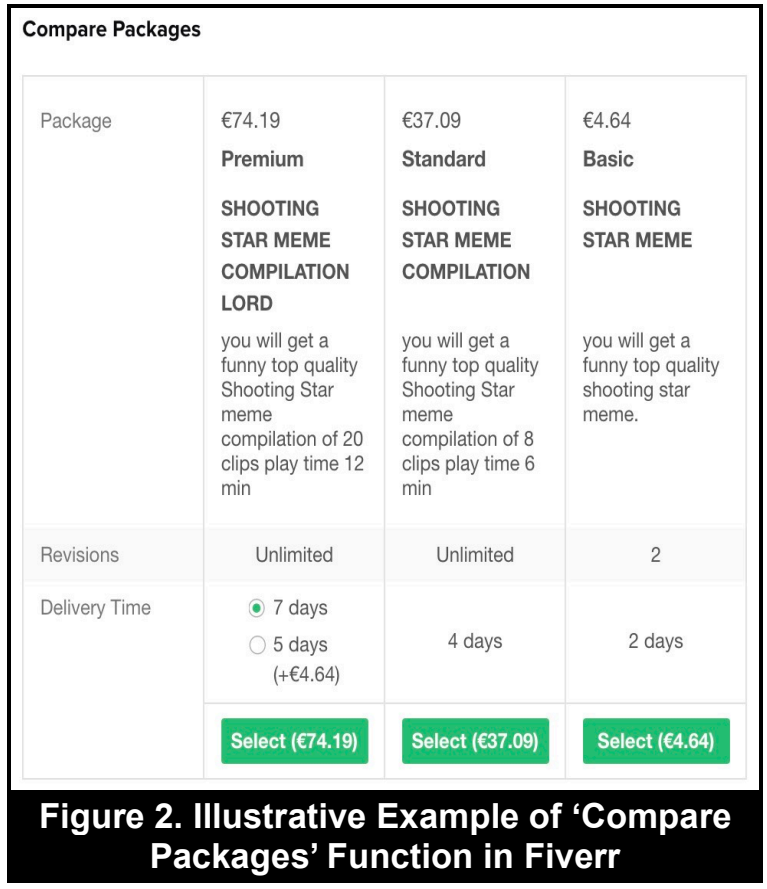

\subsection{Measurement}

4.2.1. Dependent variable. Building upon platform characteristics of Fiverr, service quality and sales were incorporated into this study as dependent variables. Specifically, service quality was measured by the score provided in comments. In Fiverr, comment score was employer's overall evaluation of a purchased gig. This indicator was based on aspects of seller communication level, willingness to recommend gig to a friend, and degree to which the service matches the description. Comment score was measured by a 5-level scale. The higher the comment score, the higher service quality of a gig. Meanwhile, due to the unavailability of actual sales figures on Fiverr, we draw on the number of consumer comments as a proxy of service sales of a gig following the recommendation of Ye, Law, and Gu [54]. Although consumers are not coerced into providing feedback for consumed services, they are prompted repeatedly by Fiverr to evaluate gig offerings after consumption. For this reason, the number of consumer comments can be construed as a conservative estimate for the number of transactions.

4.2.2. Independent variable. Independent variables in our study were measured based on service specification options of each gig. Specifically, repertoire volume was measured by the number of options provided by a gig in the function of compare packages [14, 25]. Repertoire complexity was measured as the degree to which a gig carried out a diverse repertoire of specification options by using an established formula $1-\sum_{\alpha}\left(\frac{\mathrm{N}_{\alpha}}{\mathrm{NT}}\right)^{2}$, where $\mathrm{N}_{\alpha}$ represents the number of options belonging to the $\alpha^{\text {th }}$ category in the function of compare packages, NT is the total number of options across all categories, and $\mathrm{N}_{\alpha} /$ NT denotes the proportion of options in the $\alpha^{\text {th }}$ category $[23,55]$. Repertoire heterogeneity captured the extent to which a gig differed from other gigs in terms of the number of options available in each package (i.e., basic standard, and premium). It was measured by adopting the existing formula commonly used in the competitive action literature $S_{t}\left(f_{i}, \bar{f}\right)=\sqrt{\frac{\left(\mathrm{f}_{1}-\bar{f}_{1}\right)^{2}++\left(f_{i_{2} 2}-\bar{f}_{2}\right)^{2}+\left(\mathrm{f}_{13}-\bar{f}_{3}\right)^{2}}{3}}$, where $f_{i j}$ represents the number of service specification options in package (column) $\mathrm{j}$ provided by gig $\mathrm{i}, \mathrm{i}=1,2,3, \ldots, 3307$, $\bar{f}_{j}=\sum\left(f_{1 j}, f_{2 j}, \ldots, f_{3307, j}\right) / 3307$ (where $\left.j=1,2,3\right)[33,56]$.

4.2.3. Control variable. Considering the potential impact of seller level and service type on service performance, seller level and service type of gigs were employed as control variables in our study. Specifically, once a seller registers on Fiverr and creates a gig on Fiverr, this seller is automatically labeled as a new seller. Fiverr assesses sellers' service performance each month and decides the level of sellers accordingly. Ontime delivery, great customer satisfaction, and highquality service can earn sellers a new Fiverr level and benefits [57]. In the Fiverr platform, seller level is categorized as new seller, level-one seller, level-two seller, and top-rated seller, which can reflect reputation and service quality of a seller [57]. New seller, level-one seller, level-two seller, and top-rated seller were coded as $0,1,2$, and 3 , respectively. Section of lifestyle was divided into 15 service categories including viral videos, spiritual \& healing, relationship advice, your message on..., online lessons, global culture, health, nutrition \& fitness, greeting cards \& videos, gaming, family \& genealogy, collectibles, celebrity impersonators, astrology \& readings, arts \& crafts, and others (cf. https://www.fiverr.com/categories/lifestyle? source=cat egory_tree). We therefore assigned values to the service type of gigs from 1 to 15 .

\section{Data Analysis}

Linear regression model (LRM) was employed to examine the proposed hypotheses. We specified the following models:

$$
\begin{array}{ll}
\mathrm{SQ}=\alpha_{\mathrm{i}}+\beta_{1} \mathrm{RV}+\beta_{2} \mathrm{RC}+\beta_{3} \mathrm{RH}+\beta_{4} \mathrm{SL}+\beta_{5} \mathrm{ST} & \text { Model } 1 \\
\mathrm{SS}=\alpha_{\mathrm{i}}+\beta_{1} \mathrm{RV}+\beta_{2} \mathrm{RC}+\beta_{3} \mathrm{RH}+\beta_{4} \mathrm{SL}+\beta_{5} \mathrm{ST} & \text { Model } 2
\end{array}
$$


where SQ denotes service quality, SS denotes service sales, RV represents repertoire volume, RC represents repertoire complexity, $\mathrm{RH}$ represents repertoire heterogeneity, SL represents seller level, and ST represents service type. As variables in our study were not normally distributed, log transformation was used to improve model fit [58].
The means, standard deviations, and correlations for the variables in our study are shown in Table 2. Since one inter-construct correlation was higher than 0.400 , we conducted a multicollinearity test. The Variance Inflation Factors (VIFs) for all focal constructs in our study fall below 5 , eliminating multicollinearity as a potential confound.

\begin{tabular}{|c|c|c|c|c|c|c|c|c|c|}
\hline Variable & Mean & Std Dev & SQ & SS & RV & $\mathbf{R C}$ & RH & SL & ST \\
\hline SQ & 4.42 & 1.35 & 1.000 & & & & & & \\
\hline SS & 75.87 & 224.39 & $0.116^{* * *}$ & 1.000 & & & & & \\
\hline $\mathrm{RV}$ & 7.53 & 3.718 & $0.107 * * *$ & 0.014 & 1.000 & & & & \\
\hline $\mathrm{RC}$ & 0.77 & 0.02 & 0.021 & $-0.086 * * *$ & $0.034^{*}$ & 1.000 & & & \\
\hline $\mathrm{RH}$ & 0.38 & 0.20 & $0.065^{* * *}$ & $0.041^{*}$ & $0.350 * * *$ & $-0.311 * * *$ & 1.000 & & \\
\hline SL & 0.95 & 0.95 & $0.292 * * *$ & $0.219 * * *$ & -0.018 & $-0.067 * * *$ & $0.066^{* * *}$ & 1.000 & \\
\hline ST & 8.18 & 4.33 & $-0.268 * * *$ & 0.008 & $0.042 *$ & 0.017 & 0.011 & $-0.035^{*}$ & 1.000 \\
\hline
\end{tabular}

Note: Service Quality: SQ; Service Sales: SS; Repertoire Volume: RV; Repertoire Complexity: RC; Repertoire Heterogeneity: $\mathrm{RH}$; Seller Level: SL; Service Type: ST. ${ }^{*} p<0.05 ;{ }^{* *} p<0.01 ;{ }^{* *} p<0.001$.

As is shown in Table 3, for credence goods in the emarketplace of gig economy, repertoire volume was positively related to service quality $(\beta=0.110, \mathrm{p}<0.001)$ and service sales $(\beta=0.244, \mathrm{p}<0.001)$, which supported $\mathrm{H} 1 \mathrm{a}$ and H1b. Repertoire complexity was positively associated with service quality $(\beta=1.750, p<0.01)$ but negatively related to service sales $(\beta=-5.662, p<0.01)$. Thus, $\mathrm{H} 2 \mathrm{a}$ was not supported but $\mathrm{H} 2 \mathrm{~b}$ was supported. As to repertoire heterogeneity, it had insignificant relationship with service quality $(\beta=0.119$, n.s.) and service sales $(\beta=0.264$, n.s. $)$, which did not support H3a and H3b. For control variable, seller level was tested to have positive relationships with service quality $(\beta=0.260, \quad p<0.001)$ and service sales $(\beta=1.295$, $\mathrm{p}<0.001)$. For service type, it is negatively associated with both service quality $(\beta=-0.208, \mathrm{p}<0.001)$ and service sales $(\beta=-0.424, p<0.001)$.

Table 3. Regression Results

\begin{tabular}{|c|c|c|}
\hline $\begin{array}{l}\text { Dependent Variable } \\
\text { Independent Variable }\end{array}$ & Service Quality & Service Sales \\
\hline Lg(Repertoire Volume +1$)$ & $0.110 * * *(5.420)$ & $0.244 * * *(4.157)$ \\
\hline $\operatorname{Lg}($ Repertoire Complexity+1) & $1.750 * *(2.854)$ & $-5.662 * *(-3.195)$ \\
\hline $\operatorname{Lg}($ Repertoire Heterogeneity +1$)$ & $0.119(1.455)$ & $0.264(1.118)$ \\
\hline $\operatorname{Lg}($ Sell Level+1) & $0.260 * * *(17.136)$ & $1.295 * * *(29.575)$ \\
\hline $\operatorname{Lg}($ Service Type +1$)$ & $-0.208 * * *(-15.280)$ & $-0.424 * * *(-10.786)$ \\
\hline Constant & $0.281^{\dagger}(1.832)$ & $2.616^{* * *}(5.904)$ \\
\hline$F$-test & $123.022 * * *$ & $221.536^{* * *}$ \\
\hline$R^{2}$ & $15.71 \%$ & $25.13 \%$ \\
\hline
\end{tabular}

Note: $t$-values is shown in parentheses. $R^{2}$ shows the proportion of variance in the dependent variable which can be predicted from the independent variables. ${ }^{\dagger} p<0.1 ;{ }^{*} p<0.05 ;{ }^{* *} p<0.01 ;{ }^{* * *} p<0.001$.

\section{Discussion and Implications}

This study investigates the role of service specification option repertoires in promoting service quality and sales in gig economy. First, consistent with previous studies [14], our finding unveils the positive relationship between repertoire volume and service quality and sales under the conditions of our study. The more options a seller configures in the function of compare packages, the better the service can fulfill consumers' needs. Second, our study delves into the relationship between repertoire complexity and service performance. Contrary to our expectation, repertoire complexity is positively related to service 
quality in our research context. One possible reason is that a complex repertoire of options can depict the differences between different packages. More options are available in each service specification category with a high level of repertoire complexity, which facilitates the match between service offering and consumers' needs due to more choices of customized services. Consistent to our hypothesis, repertoire complexity has negative relationship with service sales in our research context. Our findings stand in contrast to the results of Gnyawali et al. [27] and Li et al. [14], who reported that complex repertoires achieve better service sales. In the context of experiential services, complex repertoires positively associate with service sales owing to the creation of competitive differentiation and the improvement of consumers' perceived usefulness [14]. However, due to the lack of effective evaluation indicators for credence services, complex repertoires may not increase perceived usefulness but could reduce perceived ease of use [45, 46]. Complex options could thus negatively relate to the intention of consumers to purchase the service. This reveals that the role of service specification option repertoires is complicated and needs to be examined with different product categories in different platforms. Third, unexpectedly, repertoire heterogeneity is not significantly related to service quality and sales in our research context. One explanation is that the platform does not support direct comparison among packages from different sellers. It is unrealistic to expect consumers to memorize details of each service offering and make comparison in their mind to support their purchase decision making and evaluation of quality. Finally, seller level and product type have positive relationships with service quality and sales in our research context.

Findings of this study contribute to the stream of the credence service in gig economy on two counts. On the theoretical front, our study contributes to research on gig economy by shedding light on the positive relationship between service specification options and service quality and sales. Due to the lack of standardized service processes in the gig economy, sellers do not know how to efficiently specify their service offerings to reap a high service sales and quality evaluation. The repertoire of service specification option acts as an effective instrument to solve challenges faced by them. Our findings therefore contribute to CRT by extending it to credence services in the gig economy. When applying CRT in this context, it is interesting to have unexpected findings that repertoire complexity has positive link with service quality, and repertoire heterogeneity is insignificantly related to service quality and sales under the conditions of our study. On the practical front, our research provides important insights for sellers and platform developers in the gig economy. Our research can offer actionable guidelines for sellers on improving service performance by properly utilizing service specification option repertoires. Sellers are suggested to increase repertoire volume and reduce repertoire complexity to improve service quality. To boost service sales, the number of options in compare packages should be increased, but the design of feature categories in compare packages should be simple. Moreover, they do not need to consider repertoire heterogeneity in gig economy platforms. Our research also offers guidelines for platform developers on how to develop service specification options. Platforms should take steps to better design functions to compare packages across different sellers, which is conducive to the role of repertoire heterogeneity in service offerings. This endeavor helps sellers who can offer distinguished services to stand out to get consumers' attention, thereby promoting the service quality and sales of the platform as a whole.

This study has several limitations that may represent avenues for future research. First, our data were collected from one section (i.e., lifestyle) in a specific gig economy platform (i.e., Fiverr), cautions should be taken when extending the sales performance to gigs in other sections and sellers from other gig economy platforms. In other words, to ensure the generalizability of the research model, future research could replicate this work by examining sellers from different types of gigs (e.g., business, digital marketing, and writing \& translation) and in other gig economy platforms (e.g., Amazon Flex, Wonolo, and Freelancer). Moreover, re-testing CRT in other platforms should be contextualized to adjust the operationalization based on specific functions of other platforms. Second, while the number of comments has been employed as a conservative proxy for sales performance in this study due to unavailability of actual sales figures on Fiverr, future research should seek to examine the impact of competitive repertoires on actual sales performance of gig offerings. Third, only the static relationship between competitive repertoires and service performance was examined in our study. Future research can explore the relationship between the dynamic evolution of service specification options and service performance over time by analyzing longitudinal data.

\section{Acknowledgements}

The work described in this paper was supported by the National Natural Science Foundation of China (NSFC: 71801204). 


\section{References}

[1] G. Burtch, S. Carnahan, and B. N. Greenwood, "Can You Gig It? An Empirical Examination of the Gig Economy and Entrepreneurial Activity", Management Science, (64:12), 2018, pp. 5497-5520

[2] V. G. Devinatz, "Introduction to "Independent Workers: Growth Trends, Categories, and Employee Relations Implications in the Emerging Gig Economy", Employee Responsibilities and Rights Journal, (31:1), 2019, pp. 61-62.

[3] Staffing Industry Analysts, US Gig Economy Grows to USD $\$ 864$ Billion (available online at: https://www2.staffingindustry.com/About/MediaCenter/Press-Releases/US-Gig-Economy-Grows-to-USD864-Billion, accessed June 2, 2019)

[4] A. Stringfellow, Best Gig Economy Apps: 50 Leading Apps to Find Work and Live the Gig Economy Lifestyle (available online at: https://www.wonolo.com/blog/bestgig-economy-apps/, accessed June 1, 2019)

[5] Y. C. Hsieh, H. C. Chiu, and M. Y. Chiang, "Maintaining a Committed Online Customer: A Study across Searchexperience-credence Products", Journal of Retailing, (81:1), 2005, pp. 75-82.

[6] B. L. Alford, and D. L. Sherrell, "The Role of Affect in Customer Satisfaction Judgments of Credence-based Services", Journal of Business Research, (37:1), 1996, pp. 71-84.

[7] P. J. Prenshaw, S. E. Kovar, and K. Gladden Burke, "The Impact of Involvement on Satisfaction for New, Nontraditional, Credence-based Service Offerings", Journal of Services Marketing, (20:7), 2006, pp. 439-452.

[8] U. Dulleck, R. Kerschbamer, and M. Sutter, "The Economics of Credence Goods: An Experiment on the Role of Liability, Verifiability, Reputation, and Competition", American Economic Review, (101:2), 2011, pp. 526-555.

[9] K. Mortimer, and A. Pressey, "Customer Information Search and Credence Services: Implications for Service Providers", Journal of Services Marketing, (27:1), 2013, pp. 49-58.

[10] K. Mitra, M. C. Reiss, and L. M. Capella, "An Examination of Perceived Risk, Information Search and Behavioral Intentions in Search, Experience and Credence Services", Journal of Services Marketing, (13:3), 1999, pp. 208-228.

[11] M. Galetzka, J. W. Verhoeven, and A. T. H. Pruyn, "Service Validity and Service Reliability of Search, Experience and Credence Services: A Scenario Study", International Journal of Service Industry Management, (17:3), 2006, pp. 271-283.

[12] Y. Wang, Z. Qu, and B. Tan, "How do Assurance Mechanisms Interact in Online Marketplaces? A Signaling Perspective", IEEE Transactions on Engineering Management, (65:2), 2018, pp. 239-251.

[13] H. Li, Y. Fang, Y. Wang, K. H. Lim, and L. Liang, "Are All Signals Equal? Investigating the Differential Effects of Online Signals on the Sales Performance of E-Marketplace
Sellers", Information Technology \& People, (28:3), 2015, pp. 699-723.

[14] H. Li, Y. Fang, K. H. Lim, and Y. Wang, "PlatformBased Function Repertoire, Reputation, and Sales Performance of E-Marketplace Sellers", MIS Quarterly, (43:1), 2019, pp. 207-236.

[15] T. Eisenmann, G. Parker, and M. Van Alstyne, "Platform Envelopment", Strategic Management Journal, (32:12), 2011, pp. 1270-1285.

[16] F. Zhu, and M. Iansiti, "Entry into Platform-Based Markets", Strategic Management Journal, (33:1), 2012, pp. 88-106.

[17] J. Gallien, and S. Gupta, "Temporary and Permanent Buyout Prices in Online Auctions", Management Science, (53:5), 2007, pp. 814-833.

[18] S. Li, K. Srinivasan, and B. Sun, "Internet Auction Features as Quality Signals", Journal of Marketing, (73:1), 2009, pp. 75-92.

[19] C. X. J. Ou, and K. C. C. Chan, "Developing a Competitive Edge in Electronic Markets via Institutional and Social Based Quality Signaling Mechanisms", Information \& Management, (51:5), 2014, pp. 532-540.

[20] J. Bockstedt, and K. H. Goh, "Seller Strategies for Differentiation in Highly Competitive Online Auction Markets", Journal of Management Information Systems, (28:3), 2011, pp. 235-268.

[21] K. Zhu, "Information Transparency of Business-toBusiness Electronic Markets: A Game-Theoretic Analysis", Management Science, (50:5), 2004, pp. 670-685.

[22] H. Li, Y. Fang, Y. Wang, K. H. Lim, and L. Liang, "Platform-Based Online Services, Competitive Actions, and E-Marketplace Seller Performance", PACIS 2012 Proceedings, Vietnam, 2012, pp. e127.

[23] D. Miller, and M. J. Chen, "The Simplicity of Competitive Repertoires: An Empirical Analysis", Strategic Management Journal, (17:6), 1996, pp. 419-439.

[24] H. A. Ndofor, D. G. Sirmon, and X. He, "Firm Resources, Competitive Actions and Performance: Investigating A Mediated Model with Evidence from the InVitro Diagnostics Industry", Strategic Management Journal, (32:6), 2011, pp. 640-657.

[25] K. G. Smith, W. J. Ferrier, and H. Ndofor, Competitive Dynamics Research: Critique and Future Directions, Blackwell Publishers, London, 2001.

[26] W. J. Ferrier, and D. W. Lyon, "Competitive Repertoire Simplicity and Firm Performance: The Moderating Role of Top Management Team Heterogeneity", Managerial and Decision Economics 25, 6-7(2004), 317-327.

[27] D. R. Gnyawali, W. Fan, and J. Penner, "Competitive Actions and Dynamics in the Digital Age: An Empirical Investigation of Social Networking Firms", Information Systems Research, (21:3), 2010, pp. 594-613.

[28] L. Chi, T. Ravichandran, and G. Andrevski, "Information Technology, Network Structure, and Competitive Action", Information Systems Research, (21:3), 2010, pp. 543-570. 
[29] C. Zhang, P. Song, and Z. Qu, "Competitive Action in the Diffusion of Internet Technology Products in Emerging Markets: Implications for Global Marketing Managers", Journal of International Marketing, (19:4), 2011, pp. 40-60.

[30] B. L. Connelly, L. Tihanyi, D. J. Ketchen Jr, C. M. Carnes, and W. J. Ferrier, "Competitive Repertoire Complexity: Governance Antecedents and Performance Outcomes", Strategic Management Journal, (38:5), 2017, pp. 1151-1173.

[31] M. Hughes-Morgan, and W. J. Ferrier, “"Short Interest Pressure' and Competitive Behaviour", British Journal of Management, (28:1), 2017, pp. 120-134.

[32] B. L. Connelly, K. B. Lee, L. Tihanyi, S. T. Certo, and J. L. Johnson, "Something in Common: Competitive Dissimilarity and Performance of Rivals with Common Shareholders", Academy of Management Journal, (62:1), 2019, pp. 1-21.

[33] M. F. King, and S. K. Balasubramanian, "The Effects of Expertise, End Goal, and Product Type on Adoption of Preference Formation Strategy", Journal of the Academy of Marketing Science, (22:2), 1994, pp. 146-159.

[34] T. Friedrich, S. Schlauderer, and S. Overhage, "The Impact of Social Commerce Feature Richness on Website Stickiness through Cognitive and Affective Factors: An Experimental Study", Electronic Commerce Research and Applications, (36), 2019, pp. e100861.

[35] D. V. Parboteeah, J. S. Valacich, and J. D. Wells, "The Influence of Website Characteristics on a Customer's Urge to Buy Impulsively", Information Systems Research, (20:1), 2009, 60-78.

[36] R. L. Wakefield, K. L. Wakefield, J. Baker, and L. C. Wang, "How Website Socialness Leads to Website Use", European Journal of Information Systems, (20:1), 2011, pp. 118-132.

[37] K. Hassanein, and M. Head, "The Impact of Infusing Social Presence in the Web Interface: An Investigation across Product Types", International Journal of Electronic Commerce, (10:2), 2005, pp. 31-55.

[38] D. Cyr, K. Hassanein, M. Head, and A. Ivanov, "The Role of Social Presence in Establishing Loyalty in E-Service Environments", Interacting with Computers, (19:1), 2007, pp. 43-56.

[39] T. S. Teo, and S. H. Pok, "Adoption of WAP-Enabled Mobile Phones among Internet Users”, Omega, (31:6), 2003, pp. 483-498.

[40] F. D. Davis, "Perceived Usefulness, Perceived Ease of Use, and User Acceptance of Information Technology", MIS Quarterly, (13:3), 1989, pp. 319-340.

[41] P. F. Burke, "Seeking Simplicity in Complexity: The Relative Value of Ease of Use (EOU)-Based Product Differentiation", Journal of Product Innovation Management, (30:6), 2013, pp. 1227-1241.

[42] V. Swaminathan, "The Impact of Recommendation Agents on Customer Evaluation and Choice: The Moderating Role of Category Risk, Product Complexity, and
Customer Knowledge", Journal of Customer Psychology, (13:1), 2003, pp. 93-101.

[43] F. Calisir, and F. Calisir, "The Relation of Interface Usability Characteristics, Perceived Usefulness, and Perceived Ease of Use to End-User Satisfaction with ERP Systems", Computers in Human Behavior, (20:4), 2004, pp. 505-515.

[44] D. Miller, "The Architecture of Simplicity", Academy of Management Review, (18:1), 1993, pp.116-138.

[45] Y. K. Lee, J. H. Park, N. Chung, and A. Blakeney, "A Unified Perspective on the Factors Influencing Usage Intention toward Mobile Financial Services", Journal of Business Research, (65:11), 2012, pp. 1590-1599.

[46] T. Laukkanen, "Customer Adoption versus Rejection Decisions in Seemingly Similar Service Innovations: The Case of the Internet and Mobile Banking", Journal of Business Research, (69:7), 2016, pp. 2432-2439.

[47] R. A. D'Aveni, and I. C. MacMillan, "Crisis and the Content of Managerial Communications: A Study of the Focus of Attention of Top Managers in Surviving and Failing Firms", Administrative Science Quarterly, (35:4), 1990, pp. 634-657.

[48] T. L. Amburgey, D. Kelly, and W. P. Barnett, "Resetting the Clock: The Dynamics of Organizational Change and Failure", Administrative Science Quarterly (38:1), 1993, pp. 51-73.

[49] J. Barney, and A. M. Arikan, The Resource-Based View: Origins and Implications, Blackwell, Oxford, 2001.

[50] M. Zviran, C. Glezer, and I. Avni, "User Satisfaction from Commercial Web Sites: The Effect of Design and Use", Information \& Management, (43:2), 2006, pp. 157178.

[51] J. Schumpeter, Capitalism, Socialism and Democracy, Harper, New York, 1950.

[52] D. R. Gnyawali, J. He, and R. Madhavan, "Impact of Co-opetition on Firm Competitive Behavior: An Empirical Examination", Journal of Management, (32:4), 2006, pp. 507-530.

[53] R. D'Aveni, Hypercompetition: Managing the dynamics of strategic maneuvering. Free Press, New York, 1994.

[54] Q. Ye, R. Law, and Gu, B. "The Impact of Online User Reviews on Hotel Room Sales", International Journal of Hospitality Management, (28:1), 2009, pp. 180-182.

[55] C.-W. Tan, I. Benbasat, and R. T. Cenfetelli, "ItMediated Customer Service Content and Delivery in Electronic Governments: An Empirical Investigation of the Antecedents of Service Quality", MIS Quarterly, (37:1), 2013, pp. 77-109.

[56] M.-J. Chen, and D. Miller, "Competitive Dynamics: Themes, Trends, and A Prospective Research Platform", The Academy of Management Annals, (6:1), 2012, pp. 135-210.

[57] Fiverr, Fiverr's Level System, (available online at https://www.fiverr.com/levels, accessed May 30, 2019).

[58] H. Chen, P. De, and Y. J. Hu, "It-Enabled Broadcasting in Social Media: An Empirical Study of Artists' Activities and Music Sales", Information Systems Research, (26:3), 2015, pp. 513-531. 